\title{
Excellent Outcome in Midbrain Contusion: An Uncommon Report
}

\section{Bansal S* and Mahapatra AK}

Department of Neurosurgery, All India Institute of Medical Sciences, Bhubaneswar, Orissa, India

\begin{abstract}
Traumatic brain injuries are an important cause of death for patients younger than 50 years of age. Brain stem hemorrhage after blunt head injury is a rare event. The relationship between the presence of brain stem injury and clinical outcome is unclear and has varied significantly. Our case highlights an uncommon case of good outcome after midbrain contusion after severe head injury.
\end{abstract}

Keywords: Brain stem injury; Midbrain contusion; Good outcome

\section{Introduction}

Traumatic brain injuries (TBI) are an important cause of death for patients younger than 50 years of age $[1,2]$. These are associated with permanent neurologic disability and consumption of health care resources [3]. Brain stem hemorrhage after blunt head injury is a rare event. It occurs in $0.75 \%-3.6 \%$ of all patients admitted to hospital with head injury [4]. The relationship between the presence of brain stem injury and clinical outcome is unclear and has varied significantly [5]. Published literature suggests that lesions in the brain stem are associated with a worse global prognosis and less probability of recovering from a vegetative state [6]. However, there is also study published by Aguas et al. [7], they stated that brain stem injury might not necessarily predict a poor prognosis, as good recovery is reported in some patients with TBI affecting the brain stem. Our case highlights an uncommon case of good outcome after midbrain contusion.

\section{Case Report}

16 years male patient presented with history of fall from the bike with no helmet while driving. He had loss of consciousness after injury. There was no evidence of external injury over scalp. There was no history of alcohol intake at the time of admission. His GCS was E1V1M5 at the time of presentation. He had left hemiparesis (3/5, MRC Grade). His vitals were stable. NCCT Head was appearantly normal (Figure 1A). On MRI, contusions in left side of dorsal midbrain and right side of thalamus were identified (Figure 1B-1D). He was maintained on conservative management and nursing care. After one week of injury,

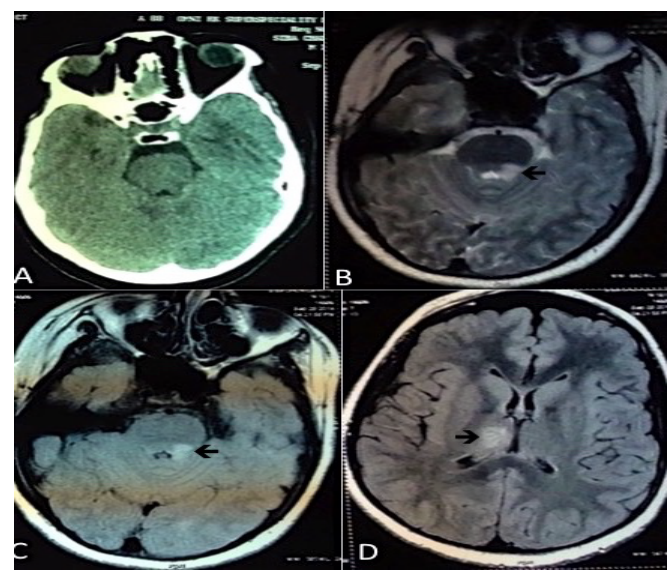

Figure 1: NCCT Head after injury was apparently normal (A), MRI brain showing left sided dorsal midbrain contusion (black arrows) $(B, C)$ with right thalamic contusion (arrow) (D). he was able to open his eyes spontaneously. Nursing care continued along with Ryle's tube feed. After about 1 month of injury, he gradually improved in sensorium and he was able to accept semisolid diet orally followed by normal diet. He was discharged in conscious state. On follow up at 2 months after injury, his GCS was 15/15, without any focal neurological deficit (Figure 2). CT head was repeated which showed resolving contusion in left side of dorsal midbrain (Figure 3). Overall he had an excellent outcome.

\section{Discussion}

Although CT is the imaging technique of choice for initial evaluation of TBI [8], MR imaging is more sensitive for the depiction of traumatic lesions in the brain parenchyma $[9,10]$ particularly in the visualization of posterior fossa structures and non-hemorrhagic lesions [5]. In a series of 108 patients with severe head injury, by Hilario et al. [11], 47\% had brain stem injuries detected on conventional MR imaging. Brain stem injuries were predominantly hemorrhagic and

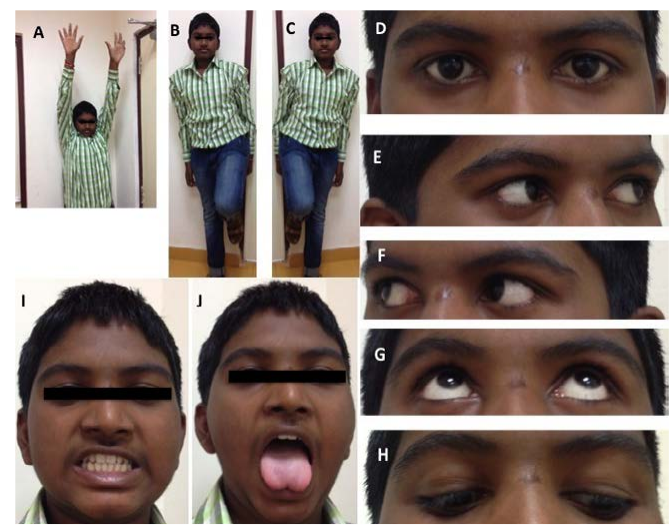

Figure 2: Follow-up after 2 months: normal motor power in both upper and lower limbs (A-C). Also showing normal extra-ocular movements with no facial or lower cranial nerve paresis (D-J).

*Corresponding author: Bansal S, Department of Neurosurgery, All India Institute of Medical Sciences, Bhubaneswar, Orissa, India, Tel: 917077192236; E-mail: drsumitbansal@gmail.com

Received February 27, 2016; Accepted April 19, 2016; Published April 29, 2016

Citation: Bansal S, Mahapatra AK (2016) Excellent Outcome in Midbrain Contusion: An Uncommon Report. Med Rep Case Stud 1: 111. doi: 10.4172/25725130.1000111

Copyright: $\odot 2016$ Bansal S, et al. This is an open-access article distributed under the terms of the Creative Commons Attribution License, which permits unrestricted use, distribution, and reproduction in any medium, provided the original author and source are credited. 
Citation: Bansal S, Mahapatra AK (2016) Excellent Outcome in Midbrain Contusion: An Uncommon Report. Med Rep Case Stud 1: 111. doi: 10.4172/2572-5130.1000111

Page 2 of 2

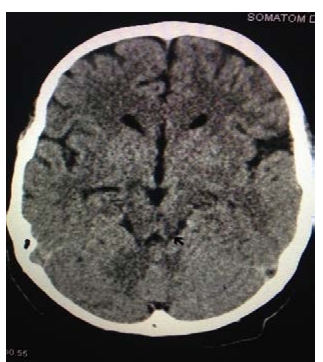

Figure 3: Follow-up NCCT Head showing resolving contusion in left sided dorsal midbrain (arrow).

$81 \%$ experienced a poor outcome. On the other hand, in the group with non-hemorrhagic brain stem injuries, $58 \%$ showed a good outcome. As per their study, non-hemorrhagic injuries showed the highest positive predictive value for good outcome and concluded that the addition of non-hemorrhagic and anterior lesions or unilateral injuries showed the best capacity for good outcome.

Our case had hemorrhagic contusion in dorsal midbrain along with right-sided thalamic contusion. As per literature, poor outcome should have been expected but excellent recovery of our case triggers new challenge in the evaluation of outcome of brain stem injury. Good outcome in our case may be explained by early presentation to hospital followed by supportive management thereby preventing secondary brain injury.

\section{References}

1. Leibson CL, Brown AW, Ransom JE, Diehl NN, Perkins PK, et al. (2011)
Incidence of traumatic brain injury across the full disease spectrum Epidemiology 22: 836-844.

2. Corrigan JD, Selassie AW, Orman JA (2010) The epidemiology of traumatic brain injury. J Head Trauma Rehabil 25: 72-80.

3. Reilly P (2007) The impact of neurotrauma on society: an international perspective. Prog Brain Res 161: 3-9.

4. Zuccarello M, Fiore DL, Trincia G, De Caro R, Pardatscher K, et al. (1983) Traumatic primary brain stem haemorrhage: A clinical and experimental study. Acta Neurochir (Wien) 67: 103-113

5. Mannion RJ, Cross J, Bradley P, Coles JP, Chatfield D, et al. (2007) Mechanismbased MRI classification of traumatic brainstem injury and its relationship to outcome. J Neurotrauma 24: 128-135.

6. Levin HS, Williams D, Crofford M (1988) Relationship of depth brain lesions to consciousness and outcome after closed head injury. J Neurosurg 69: 861-866.

7. Aguas J, Begue R, Diez J (2005) Brainstem injury diagnosed by MRI. An epidemiologic and prognostic reappraisal. Neurocirugia 16: 14-20.

8. Marshall LF, Marshall SB, Klauber MR, Clark MB, Eisenberg HM, et al. (1991) A new classification of head injury based on computed tomography. J Neurosurg 75: $14-20$.

9. Skandsen T, Kvistad KA, Solheim O, Lydersen S, Strand IH, et al. (2011) Prognostic value of magnetic reso-nance imaging in moderate and severe head injury: A prospective study of early MRI findings and one-year outcome. J Neurotrauma 28: 691-699.

10. Lagares A, Ramos A, Alday R, Ballenilla F, Pérez-Nuñez A, et al. (2006) Magnetic resonance in moderate and severe head injury: Comparative study of CT and MR findings. Characteristics related to the presence and location of diffuse axonal injury in MR. Neurocirugia 17: 105-118.

11. Hilario A, Ramos A, Millan JM, Salvador E, Gomez PA, et al. (2012) Severe traumatic head injury: Prognostic value of brain stem injuries detected at MRI Am J Neuroradiol 33: 1925-1931. 